\title{
Pelvic pain, pelvic organ prolapse, urinary and colorectal distress incidence and relationship to quality of life and birth mode
}

Lori Maria Walton*, Christine Abreu, Eliena Jeffus, Amy Trautwein and Shenya Xavier

*Correspondence: loriptdoc@gmail.com

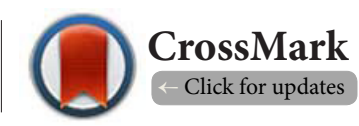

Andrews University, Department of Physical Therapy, School of Health Sciences, 8515 E Circle Dr., Berrien Springs, Michigan 49103, USA.

\begin{abstract}
Purpose: To determine the incidence and impact of pelvic pain, pelvic organ prolapse, urinary and colorectal distress and quality of life by birth mode for women in the chronic postpartum period.

Study design: Cross-sectional correlational design utilizing purposive sampling of $(n=21)$ female postpartum subjects ages $18-45$.

Background: Caesarean Section (CS) incidence is reported at $32 \%$ nationwide, well above the recommended safe rate of $10 \%(\mathrm{WHO})$. Literature is not clear regarding role of birth mode in postpartum symptoms including: pelvic pain, colorectal distress, pelvic organ prolapse, and quality of life.

Methods: Data collection took place after IRB approval from Andrews University. Each subject who agreed to volunteer for the study and met the inclusion criteria completed (1) Health History Questionnaire, (2) SF36, and (3) Pelvic Floor Distress Inventory.

Result: Incidence reports of UI were $80 \%$ in CS and 50\% in the NVD group. The CS reported significantly higher mean scores for PFIQb, UDI, POPDI and CRADI. Age was negatively correlated with CRADI and pain (Chi-square $=7.02, \mathrm{p}=0.030$ ). NVD reported a significantly higher quality of life (as measured by the SF-36) in general and mental health compared to published norms and CS $(\mathrm{p}<0.05)$. BMI showed a significant moderate correlation $(\mathrm{r}=0.682, \mathrm{p}<0.001)$ with pelvic organ prolapse.

Conclusion: Our study found significant increased incidence and impact of UI, CRADI, POPDI and PFIQb symptoms and a decrease in QOL in CS compared to NVD. Age showed significant correlation with colorectal symptoms and BMI showed significant relationship to pelvic organ prolapse.
\end{abstract}

Keywords: Pelvic pain, postpartum, pelvic floor, incontinence, colorectal pain, birth mode, caesarean section, vaginal delivery, SF-36, PFDI

\section{Introduction}

In the past two decades, within the United States, there has been a substantial rise in the number of Caesarean sections (CS). Caesarean sections comprised $32 \%$ of all deliveries ranking the USA third in the world for the most CS only behind Italy and Portugal $[1,2]$. Previously this procedure was implemented to reduce adverse risks for the fetus, with the added risk of complications for the mother minimally considered [3]. However rising cesarean rates can be attributed to the maternal concern and prevention of pelvic floor damage as well as urinary incontinence (UI), which have been highlighted in medical practice and touted as common symptoms of post-vaginal delivery $[1,4-7]$. However, some of the literature reports natural vaginal delivery (NVD) as the best alternative to heal the female body [8]. According to the World Health Organization the countries with the lowest cesarean rates also experience the lowest perinatal and maternal mortality, with the recommended "safe" cesarean rates reported at 10\% [9].

Despite advances in medical treatment, it remains uncertain whether birth mode has a clinically significant effect on postpartum symptoms [4] such as pelvic pain, pelvic organ prolapse, urinary and colorectal-anal distress, and quality of 
Walton et al. Physical Therapy and Rehabilitation 2015,

life. Almeida et al., (2002) in a study of 199 women found that $67.2 \%$ of women experiencing chronic pelvic pain had a history of CS [10]. Fabris et al., (2011) concluded that chronic pelvic pain was more relevant after a CS compared to NVD, although pelvic pain is common with both [11]. And Beiring et al., (2011) reported that pelvic pain occurred most frequently in the second half of the gestational period and spontaneously disappeared in the postpartum period [12]. Pregnancy-related pelvic pain is not a readily understood concept, however it is suggested that strenuous work, smoking, prenatal low back pain and previous pregnancy-related pelvic pain are risk factors for pelvic pain in the postpartum period [13].

It is essential to assess the health related quality of life for women in the postpartum period to provide a standardized measurement for the effect of pelvic and colorectal distress on physical, mental, and social-emotional domains in physical therapy evaluation, examination, and interventions. Physical symptoms in the postpartum may include urinary stress, urge, overflow, or mixed incontinence, colorectal-anal distress, pelvic pain, and pelvic organ prolapse, which may compromise the health related quality of life for women living in their prime years of function. When comparing NVD and CS, Torkan et al., found those with NVD reported higher marks in all areas assessing quality of life except "satisfaction towards delivery". They concluded that CS did not improve the quality of life for the mother postpartum [14].

A wide variety of physical symptoms may arise during the postpartum period, leading to decreased quality of life. Further information regarding the connection between specific postpartum symptoms and the birth mode is needed to direct evaluation, examination, and treatment for women in the chronic postpartum period. Cesarean deliveries are at an all-time high and exceeds the WHO (2010) recommended level of $15 \%[\mathbf{1}, \mathbf{2}, \mathbf{9}]$. Therefore, there is need for further research comparing CS to NVD and the effect that birth mode may have on the postpartum period. Women need to be informed of the effects of birth mode including risks for pelvic pain, pelvic organ prolapse, urinary and colorectal-anal distress and health related quality of life.

The purpose of this study was to determine the incidence and impact of pelvic pain (PP), pelvic organ prolapse (POPDI), urinary and colorectal distress (CRADI) and their relationship to quality of life $(\mathrm{QOL})$ and birth mode in women during the chronic postpartum period. The secondary research questions of this study were as follows: (1) Is there a difference in Urinary Incontinence, Pelvic Pain, and HRQOL in postpartum women based on birth mode, socioeconomic status, education level and age? (2) Is there a difference in Urinary Distress Inventory, Colorectal-Anal Distress Inventory, and Pelvic Organ Prolapse Distress Inventory in the postpartum women based upon age? (3) Is there a correlation between multiparty and the severity of UI and Pelvic Pain in postpartum women? (4) Is there a relationship between the performance of exercise, during pregnancy, and UI, pelvic pain or QOL in the postpartum period? (5) Is there a relationship between iron deficiency and comorbidities and iron deficiency and quality of life? (6) Is there an influence of BMI (body mass index) and report of comorbidities in postpartum women?

\section{Materials and methods \\ Subjects}

This study used a purposive sampling of 21 female subjects recruited from daycare facilities in a local region. Each subject who volunteered, was a women between the ages of 18 and 45 who had given birth one or more times by Caesarean Section or Natural Vaginal delivery in the past 36 months. Subjects were excluded from participation if they had history of physical therapy treatment for pelvic floor dysfunction/ incontinence, history of surgery, systemic neurologic disease or trauma affecting bowel or bladder and have given birth to more than two offspring at a time.

\section{Research design and variables}

A cross-sectional, correlational research design was used for this study. The outcome measures were analyzed according to birth mode and included the quality of life as measured by SF-36 (version 2), pelvic pain, urinary and colorectal distress, pelvic organ prolapse, and urinary incontinence impact as measured by Pelvic Floor Distress Inventory and other comorbidities listed in the Health History Questionnaire. Other variables pertaining to the secondary research questions included age, ethnicity, socioeconomic status, education level, BMI (height/weight), exercise, and iron deficiency were included in the correlation analysis.

\section{Procedures}

Approval for this study was obtained from IRB in November 2012 and facility permission was obtained prior to the initiation of this study. Each subject who agreed to participate in this research study read and voluntarily signed the informed consent and were given three inventories to complete: a Health History Questionnaire (created by co-researchers), the SF-36 (version 2), and the Pelvic Floor Distress Inventory (PFDI), which included the Urinary Distress Inventory (UDI-6), Colorectal-Anal Distress (CRADI-8), Pelvic Organ Prolapse Distress Inventory (POPDI-6), and Pelvic Floor Impact Questionnaire (PFIQ). These surveys were chosen to evaluate the quality of life relationship with urinary and colorectal distress, pelvic pain, pelvic organ prolapse, and other co-morbidities.

All data collected by the co-investigators were locked in a cabinet in the primary researcher's office, with only the primary researcher having access to the key. Data were de-identified upon coding into SPSS, which was used for statistical analysis, and analyzed by co-investigators.

\section{Instrumentation}

The Pelvic Floor Distress Inventory measures the quality of life based upon pelvic floor symptoms such as pelvic floor pain 
with an excellent test-retest reliability coefficient of $r=0.86$, $\mathrm{p}<0.001$ [15]. Included in the Pelvic Floor Distress Inventory, is the urinary distress (UDI-6), with $r=0.86$, Colorectal-Anal Distress (CRADI-8), $r=0.82$, Pelvic Organ Prolapse Distress (POPDI-6), $r=0.93$, and Pelvic Floor Impact Questionnaire (PFIQ), $r=0.0862$ [15]. The SF-36 survey questionnaire, with a reliability coefficient of $r=0.92$, [16] measures the health perception of subjects as it relates to health related quality of life through physical and mental domain scores.

\section{Analysis}

All data were analyzed using the SPSS Statistical program, version 20.0. A Spearman Rho correlation was used to answer research questions dealing with correlations. A Mann Whitney $\mathrm{U}$ was used to find out the differences between two groups, Kruskal Wallis was utilized to analyze data concerning differences between more than two groups and One Way t-test was utilized to compare SF-36 health related quality of life norms to the sample for this study by age group.

\section{Results}

Although our study included 21 women from the ages of 18 to 45 , the majority of the subject population came from women ages 30 to 39 (69.1\%) with the most common age being 32 years old. Within the 21 subjects, $71.4 \%$ currently reported postpartum symptoms based upon their first child. $76.2 \%$ of the sample subjects were Caucasian. Seventy nine percent of the subjects had at least a four-year college degree and the majority $(76.1 \%)$ of subjects reported a household income of 70k or greater. Table 1 gives more demographic percentages as well as specific concerns regarding the presence of pelvic pain and urinary incontinence.

The caesarean section group reported a higher percentage of urinary incontinence $(90 \%)$, as well as increased incidence of pelvic pain (CS-66.7\%, NVD-23.1\%, $\mathrm{p}<0.05)$, compared

Table 1. Demographic percentages on total sample.

\begin{tabular}{ll}
\hline Vaginal delivery & $76.2 \%$ \\
Caesarean section & $23.8 \%$ \\
Pelvic pain & $76.2 \%$ \\
Urinary incontinence & $57.1 \%$ \\
BMI (Body Mass Index) & $57.1 \%(\geq 25)$ \\
Sedentary & $33.3 \%$ \\
Exercised 2-3 times/wk & $28.6 \%$ \\
Exercised 4-5 times/wk & $28.6 \%$ \\
Exercised 7 days/wk & $9.5 \%$ \\
Iron deficiency & $28.6 \%$ \\
Postpartum period & -- \\
6-11 months & $14.3 \%$ \\
12-24 months & $66.7 \%$ \\
25-36 months & $19.1 \%$ \\
Comorbidities & $52.4 \%$ \\
Complications & $71.4 \%$ \\
\hline
\end{tabular}

to the natural delivery group (50\%). (See Figures 1 and 2 ) In addition, the separate mean scores of the Urinary Distress Inventory, Colorectal-Anal Distress Inventory, and the Pelvic Organ Prolapse Distress Inventory were higher in the caesarean section group versus the natural vaginal delivery group $(p<0.05)$, see Figures $\mathbf{3 , 4}$ and $\mathbf{5}$.

\section{Birth mode, socioeconomic status, education level and age}

No significant difference was found between the variables

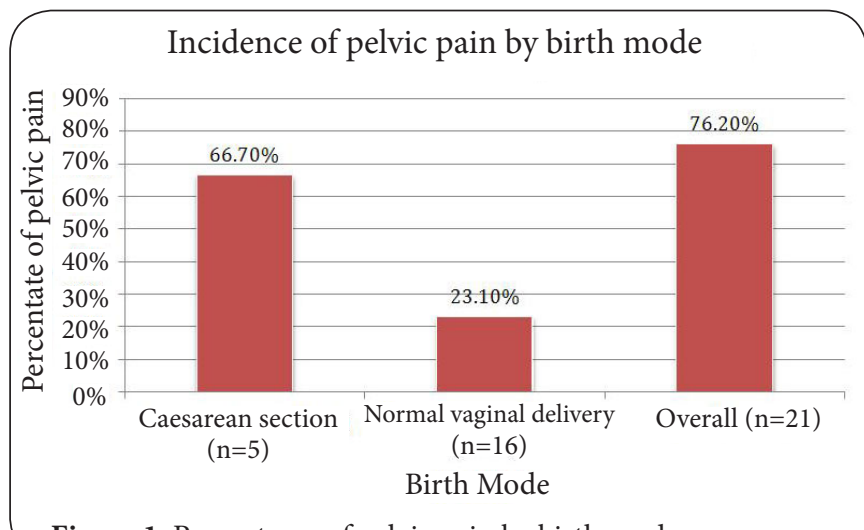

Figure 1. Percentages of pelvic pain by birth mode.

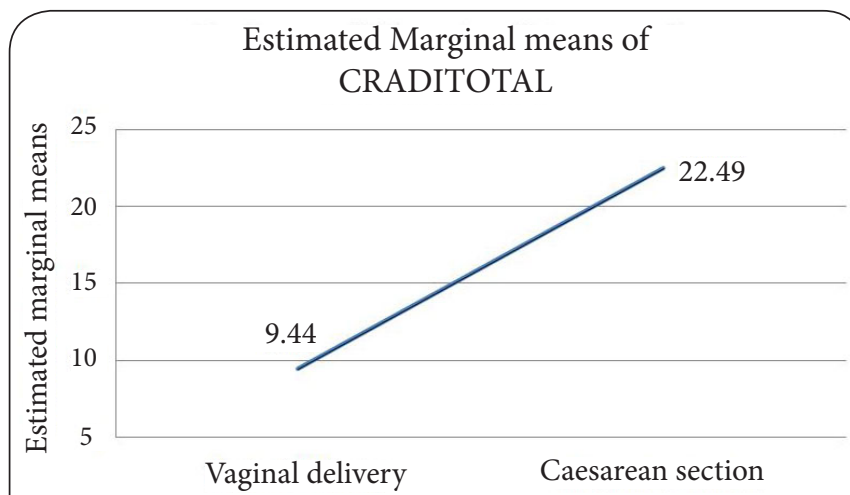

Figure 2. Marginal means of colorectal-anal distress inventory by birth mode.

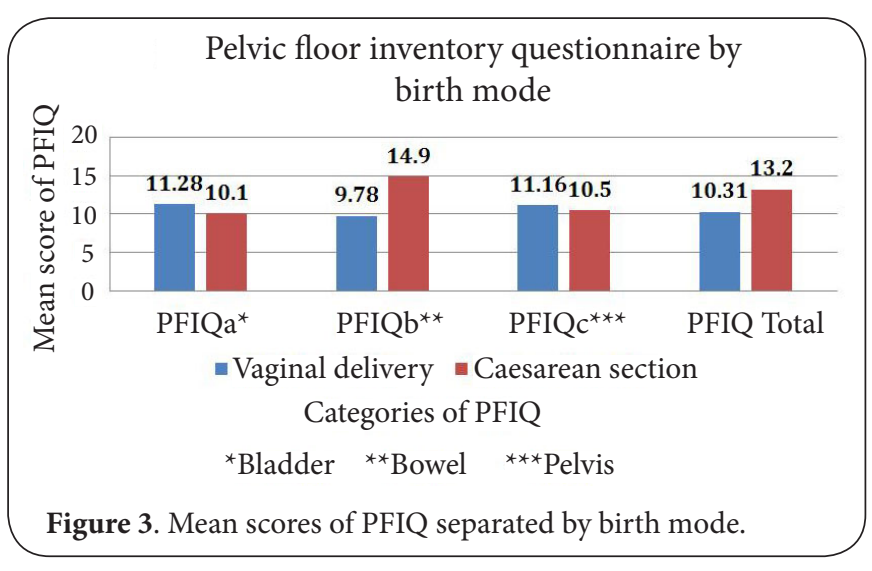


Walton et al. Physical Therapy and Rehabilitation 2015,

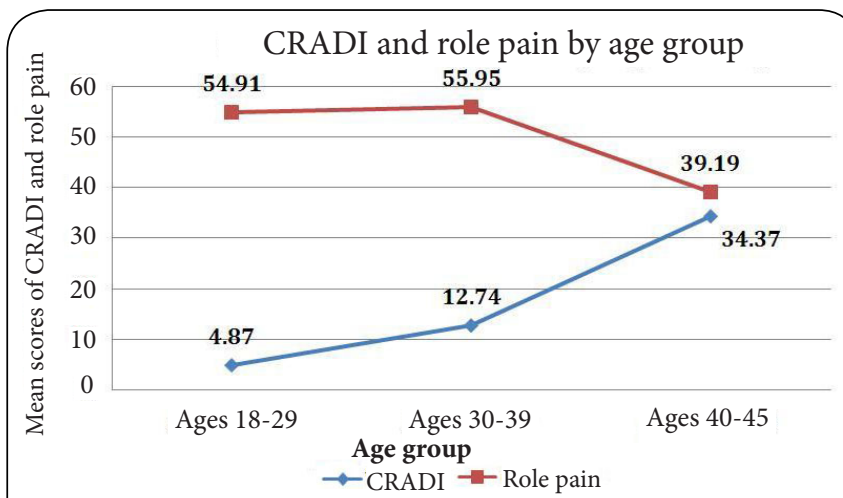

Figure 4. Mean scores of CRADI and role pain by age groups.

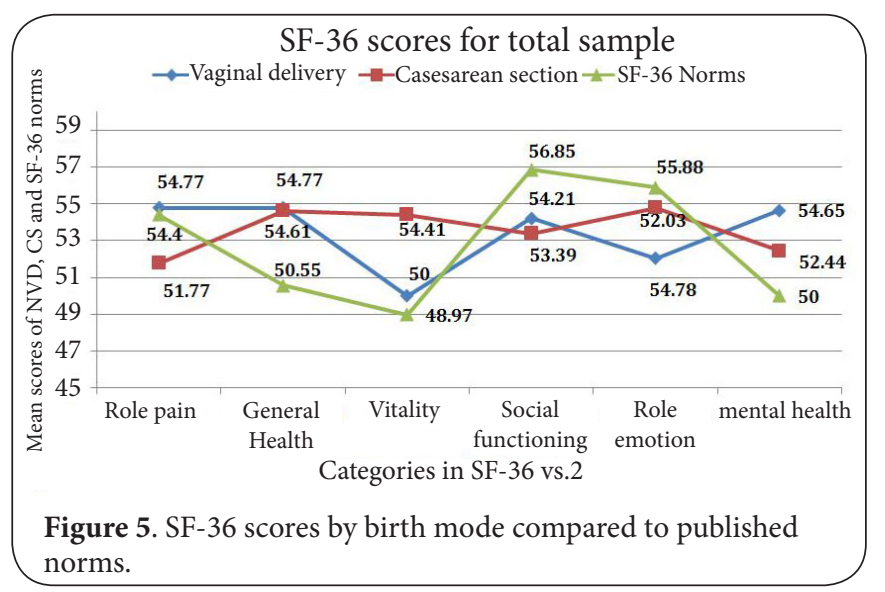

according to socioeconomic status or education level. However, by birth mode, the CS group was found to have a significantly higher mean score of 14.90 in the Pelvic Floor Inventory Questionnaire, concerning bowel, compared to the NVD group mean score of 9.78 with a significance of $\mathrm{p}=0.31(\mathrm{U}=20.5, \mathrm{df}=20)$ (Figure 6). A significant difference was also found for the PFIQ total between the age groups (Chi-Square $=3.78, d f=20, p=0.31$ ), with the highest reporting score of symptoms being in the 35 to 45 year old age group.

\section{UDI, CRADI, POPDI and age}

A significant difference was found between age groups for the CRADI (Chi-Square $=7.02, p=0.030$ ). The subjects age was directly correlated to CRADI total scores, showing greater impact during the postpartum period for colorectal-anal distress as shown in Table $\mathbf{2}$ for women in the advanced age group. A significant difference was also found by age group in role of pain (Chi-Square $=6.99, p=0.030$ ), one of the categories in the SF-36 dealing with quality of life in the postpartum period [17]. No other significant differences were found in POPDI or UDI by age group.

\section{Health related quality of life}

A significantly higher general health quality of life mean was

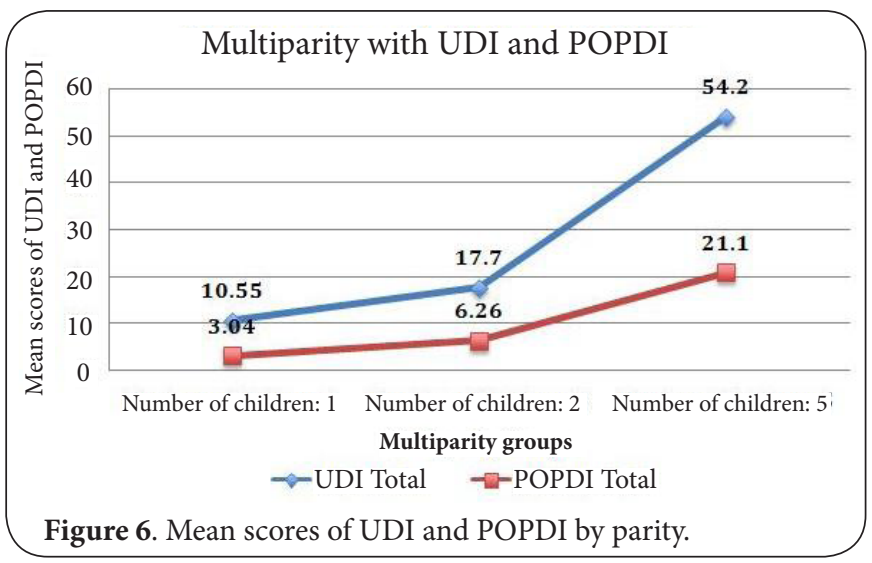

Table 2. Mean scores of UDI, POPDI, CRADI by age groups.

\begin{tabular}{lll}
\hline By Age & & Mean \\
\hline UDI TOTAL & Ages 18-29 & 1.85336 \\
& Ages 30-39 & 4.09322 \\
& Ages 40-49 & 19.400 \\
\hline POPDI TOTAL & Ages 18-29 & 1.89814 \\
& Ages 30-39 & 1.08408 \\
& Ages 40-49 & 8.3500 \\
\hline CRAD TOTAL & Ages 18-29 & 3.39663 \\
& Ages 30-39 & 2.91358 \\
& Ages 40-45 & 6.2500 \\
\hline
\end{tabular}

reported compared to the published norms utilizing a oneway $t$-test for mean comparisons $(Z=7.78, d f=20, p=0.003)$ utilizing the SF-36. As noted in Table 3, looking at the total sample and respective means for each SF-36 category, it was reported that the mean for the 21 subjects was significantly higher for mental health average compared to the norms with significance of $(Z=5.58, d f=20, p=0.003)$. However, the total sample had a significantly lower social functioning mean as well as significantly lower role emotion (Social functioning$\mathrm{Z}=1.25, \mathrm{df}=20, \mathrm{p}=0.023$, Role emotion $-\mathrm{Z}=1.69, \mathrm{df}=20, \mathrm{p}=0.038$ ).

Table 3. Comparison of participants SF-36 category means to SF-36 published norms and percentage of participants under the published norms.

\begin{tabular}{llll}
\hline SF-36 Category & $\begin{array}{l}\text { \% Of subjects } \\
\text { under SF-36 } \\
\text { Norms }\end{array}$ & $\begin{array}{l}\text { Participant's } \\
\text { Mean }\end{array}$ & $\begin{array}{l}\text { SF-36 Published } \\
\text { Norms }\end{array}$ \\
\hline Role pain & $24 \%$ & 54.06 & 54.40 \\
General health & $33.3 \%$ & 56.40 & 50.55 \\
Vitality & $38 \%$ & 50.34 & 48.97 \\
Social function & $29 \%$ & 53.76 & 56.85 \\
Role emotion & $33.3 \%$ & 52.69 & 55.88 \\
Mental health & $19 \%$ & 54.12 & 50.00 \\
\hline
\end{tabular}


A significantly higher general health mean was reported by the NVD group compared to the published norms $(Z=1.77$, $\mathrm{df}=20, \mathrm{p}=0.002$ ). The NVD also reported a significantly lower role emotion compared to published norms with significance of $Z=1.34, d f=20, p=0.027$. Lastly, the NVD reported a significantly higher mental health mean compared to the CS group $(\mathrm{Z}=5.78, \mathrm{df}=20, \mathrm{p}=0.006)$.

\section{Multiparity}

A Spearman-Rho correlation was calculated to analyze the relationship between multiparity and reported severity of $\mathrm{UI}$ and PP in postpartum women. A significant, but weak correlation was found between multiparity and UDI ( $r=0.470$, $\mathrm{p}=0.032$ ). In addition, a significant and moderate correlation was found between multiparity and POPDI ( $r=0.517, p=0.008)$. A significant, but weak correlation was found for the caesarean section group between POPDI and multiparity $(r=0.198$, $p=0.014$ ). One subject had 5 children. She reported increased co-morbidities as well as urinary incontinence, pelvic pain and decreased quality of life far greater than all other subjects.

\section{Iron deficiency and exercise}

A moderate and significant relationship was found between iron deficiency and comorbidities. Furthermore, a significant and moderate correlation was found between those subjects who exercised and reported having iron deficits in the prenatal period $(r=0.627, p=0.022)$.

\section{Body mass index}

BMI (Body Mass Index) was calculated from the subject's reported height and weight during the postpartum period. A significant and moderate correlation $(r=0.682, p=0.001)$ was found between those who had a BMI greater than 25 (considered overweight by BMI classification from the World Health Organization) [18] and the Pelvic Organ Prolapse Distress Inventory. No significant difference was found between the groups CS and NVD.

\section{Exercise}

Our study found that exercise had a significant, but weak correlation with role emotion during the postpartum period $(r=0.479, p=0.028)$. Table 4 shows those who exercised regularly during their prenatal period had a greater role emotion score on the SF-36 showing better control of their emotions during the postpartum period compared to those who did not exercise regularly.

\section{Discussion}

Pregnancy causes mechanical and hormonal changes to the maternal body that can lead to pelvic pain, pelvic organ prolapse, and urinary and colorectal-anal distress. Our study found increased incidence of $\mathrm{UI}$ and pelvic pain in subjects who reported CS compared with NVD. Some studies contrast our findings of occurrence of $\mathrm{Ul}$ and pelvic pain in those who
Table 4. Mean scores of role emotion by exercise amount during prenatal period.

\begin{tabular}{ll}
\hline Exercise amount & Role emotion mean \\
\hline None & 5.88 \\
Once in a while (not regularly) & 11.50 \\
A few times a week & 11.00 \\
4-5 times a week & 13.00 \\
Everyday & 14.50 \\
\hline
\end{tabular}

had a caesarean section compared to a NVD. In 2007, Press et al., found caesarean section reduced the risk for urinary incontinence from $16 \%$ to $9.8 \%$ in 6 different studies [4]. Andrews et al., found that UI was more than four times as common after a vaginal delivery then caesarean section [19]. Groutz et al., reported that UI was less common following elective CS with no trial of labor, compared to vaginal deliveries [5]. Hannah et al., found a decrease in Ul of $4.5 \%$ from mothers who had a caesarean section compared to natural vaginal delivery [3]. Groutz and Hannah also propose that those who experienced a CS had higher risk for UI during the postpartum period due to pelvic floor injury on initial trial of labor. However, none of the studies sampled women in the chronic postpartum period, as was done in our study.

Similar findings to our study reported significant incidence of $\mathrm{UI}$ in the CS sample compared to NVD $[20,21]$. Movahedi et al., found a $1 \%$ higher occurrence of $\mathrm{Ul}$ in caesarean section versus vaginal delivery [22]. Another study concluded the protective effects of CS upon incontinence are complex, yet there seems to be a strong effect on the prevention of pelvic organ prolapse and elective caesarean section [23].

Our research found a significantly higher incidence of pelvic pain as well as pelvic distress, specifically in CRADI and PFIQ (bowel) compared to NVD, in the chronic postpartum period. Some of the literature reports $2-5 \%$ of mothers will still have pelvic pain at 3 to 12 months after delivery, continues to be a factor in their daily lives (more chronically) [12]. Our study reported $76.2 \%$ of pelvic pain in the chronic postpartum period (6 to 36 months).

Our study found that with an increase in age, over 35 , came a significant increase in the impact and incidence of colorectal -anal distress as well as a decreased quality of life. Nevertheless, there are many factors that need to be accounted for such as age, body mass index, number of births, and presence of UI prepartum $[\mathbf{5 , 2 4 ]}$. The older the mother the greater potential of having UI postpartum as well as the presence of UI before the gestational period. Research alludes to decreased pelvic musculature strength as being one of the main reasons for increased postpartum symptoms as well as previous trauma to the pelvic organs [25]. The increased postpartum comorbidities may have a negative impact on the quality of life of the mother during her postpartum period. A study by Movahedi et al., (2013) found similar reports of a 3\% increase in the occurrence of urinary incontinence and pelvic symptoms per 
Walton et al. Physical Therapy and Rehabilitation 2015,

http://www.hoajonline.com/journals/pdf/2055-2386-2-1.pdf

doi: 10.7243/2055-2386-2-1

year of increased age of the mother [22].

Health related quality of life consists of broad constructs that cover various aspects of life including physical, mental, and general health and wellbeing. According to Torkan et al., assessment of the quality of one's life is necessary in-order-to accurately assess their health system. Urinary incontinence, pelvic pain, hemorrhaging and infections are common postpartum maternal complications that are evaluated. However socio-economic status, marital status, education level, employment state, and total income level are factors that are often over looked and yet can greatly alter the mother's quality of life, both physically and mentally [20].

Employment status and level of income have a great impact on the presence and amount of insurance the mother will have, which relates to the payment sources and coverage that the patient will have to pay after the birth, as well as the amount of medical services received. Cesarean sections are considered surgical and are therefore billed as such in the hospital. Monetary resources may also contribute to physiological stress on the mother [26] that may affect the quality of life during the postpartum period. The added stress of having to pay even more for a procedure (elective or nonelective) as well as the physical stress of recovery will impact the mother's life in the acute postpartum period.

Although the current study did not find significant difference for variables by socioeconomic status, psychological stress as well as socioeconomic factors may have a role in the physical health of the mother in the postpartum period, all which affect the quality of life. Socioeconomic status was found to have a direct correlation with pelvic pain in one study [12]. It is common for women from low socioeconomic class to have limited health insurance coverage and lower disposable income to receive adequate physical care potentially causing and increasing pelvic pain occurrence or severity during the postpartum period [23]. However, the relationship between socioeconomic status and pelvic pain needs to be further explored.

The means for health related quality of life were found to be above the general population norms as measured by the SF-36V2 for the subjects in the current study with respect to specific sections of general health and mental health. This has interesting implications for our study, which showed mental and general health may be very high but mothers may still be experiencing significant amounts of physical symptoms including pain, pelvic distress and incontinence.

Social functioning was significantly lower in the current sample when compared to the published norms. This may indicate that urinary incontinence and pelvic distress can affect social norms during the postpartum period for the mother. In a study by Leroy and Lopes, it was found that social function scores were higher in those with UI [27]. Balci et al., reported that incontinence tends to increase feelings of shame, which in turn will decrease their confidence as well as social well being, concluding that individuals with UI have a lower quality of life $[\mathbf{2 7}, \mathbf{2 8}]$.

The present study found a direct correlation between parity and $\mathrm{UI}$, as well as between parity and POPDI. This is supported by research that reports mothers who have elective caesarean section had a higher risk for UI when compared to nulliparous women [9]. The number of births also plays a major role in the amount of injury to the pelvic floor. Despite the fact that the first vaginal delivery will cause the most harm to the pelvic floor, subsequent deliveries will also cause an increase in the risk of UI [9]. Multiparous women who had previous injury to the pelvic region are known to cause a delayed response in healing which may contain scar tissue from previous births, specifically with caesarean delivery [23].

This study found that there was a significant correlation with exercise during the prenatal period and iron deficiency in postpartum. Interestingly, research reports that individuals who have low iron in their blood or anemia will have altered ability to adequately exercise [22]. In addition, the literature reports loss of iron through sweat when performing strenuous activities [22]. Further research is needed to explore the overall effect of iron deficiency for women who exercise during the prenatal period and other complications and comorbidities.

The present study found that BMI had a significant, moderate correlation with increase in pelvic organ prolapse. Having a higher than normal BMI (>25) was related to higher pelvic organ prolapse in the postpartum period. A similar finding was reported that concluded for every 1 unit of BMI over the established health weight category (between 18.4-24.9) there was an $8 \%$ increase in risk for postpartum urinary incontinence [23]. Another study found that women who are overweight (BMI>24.9) are more prone to severe pelvic pain [12].

There is conflicting research information as to whether exercise increases or decreases the fetal and maternal risk. The American College of Obstetricians and Gynecologists (ACOG) has changed their position statements over the years pertaining to the appropriate types, durations and intensities that are healthy for mother and baby. However over most recent years the ACOG recommends pregnant women with no complications should exercise, even those who were not active prior to conception [27]. Exercising has been found to decrease incidence of preeclampsia, gestational diabetes, low back pain, anxiety, nausea, heartburn, insomnia, leg cramps, excessive weight gain, and the necessity for caesarean section [28]. Miquelutti et al., found a significant reduction in the incidences of urinary incontinence in women who exercised during their pregnancy by $41 \%$; In the Stafne et al., study they found an $11 \%$ decrease in urinary incontinence during the postpartum period [30]. In another study by Gaston et al., it was determined women who exercised during pregnancy at a moderate to vigorous level increased their quality of life, which agreed with our findings of increased role emotion during the postpartum period for those who moderately exercised prenatally [30]. Therefore exercise is one of the best self controlling factors during pregnancy that has shown to 
Walton et al. Physical Therapy and Rehabilitation 2015,

improve the postpartum quality of life in multiple ways.

\section{Conclusion}

Authors in the current study found that cesarean section increased the risk of urinary incontinence, colorectal-anal distress and pelvic organ prolapse symptoms significantly compared to subjects who reported a vaginal delivery. Multiparity was associated with higher UDI and POPDI scores, particularly in those who had caesarean section. Age, 40-45 years, was associated with greater colorectal symptoms and pain compared to younger age groups. Exercise intensity and duration were directly related to iron deficiency during the postpartum period for this sample. Finally, increased BMl greater than 25, was associated with significant increase in pelvic organ prolapse. Future research should focus on evaluation, examination, and intervention in the chronic postpartum period and relationship to caesarean section postpartum dysfunction including pelvic pain, urinary and colorectal distress, pelvic organ prolapse.

\section{Limitations}

Limitations in the current study include a small cohort, missing data for some of the SF-36 (version 2), length of survey, lack of ethnic diversity, and limited geographical location.

\section{Future research}

Based upon the findings of our study, future research should focus on the role of colorectal-anal, pelvic organ prolapse and pelvic pain originating from bowel dysfunction for women with CS in the postpartum period. Physical Therapy treatment interventions to address colorectal-anal pain, urinary incontinence, and pelvic pain, with age and birth mode as additional factors, should be considered. Additionally, interventions to assist with postpartum reduction of $\mathrm{BMI}$ and its relationship to urinary and colorectal pelvic symptoms, as well as the relationship between iron deficiency and moderate to high levels of exercise in the prenatal and postpartum periods should be considered for future research.

\section{Competing interests}

The authors declare that they have no competing interests.

\section{Authors' contributions}

\begin{tabular}{|l|c|c|c|c|c|}
\hline Authors' contributions & LMW & CA & EJ & AT & SX \\
\hline Research concept and design & $\checkmark$ & -- & -- & -- & -- \\
\hline Collection and/or assembly of data & -- & $\checkmark$ & $\checkmark$ & $\checkmark$ & $\checkmark$ \\
\hline Data analysis and interpretation & $\checkmark$ & -- & -- & -- & -- \\
\hline Writing the article & $\checkmark$ & $\checkmark$ & $\checkmark$ & $\checkmark$ & $\checkmark$ \\
\hline Critical revision of the article & $\checkmark$ & -- & -- & -- & -- \\
\hline Final approval of article & $\checkmark$ & -- & -- & -- & -- \\
\hline Statistical analysis & $\checkmark$ & $\checkmark$ & -- & $\checkmark$ & -- \\
\hline
\end{tabular}

\section{Acknowledgement}

Thanks to Andrews University and the facilities and women who volunteered to participate in this study.

\section{Publication history}

Editor: Mohammad H. Hadadzadeh, Wheeling Jesuit University, USA. Received: 21-Sep-2014 Final Revised: 10-Dec-2014

Accepted: 08-Jan-2015 Published: 14-Jan-2015

\section{References}

1. Declercq $E$, Young $R$, Cabral $H$ and Ecker J. Is a rising cesarean delivery rate inevitable? Trends in industrialized countries, 1987 to 2007. Birth. 2011; 38:99-104. | Article | PubMed

2. Villar J, Valladares E, Wojdyla D, Zavaleta N, Carroli G, Velazco A, Shah A, Campodonico L, Bataglia V, Faundes A, Langer A, Narvaez A, Donner A, Romero M, Reynoso S, de Padua KS, Giordano D, Kublickas M and Acosta A. Caesarean delivery rates and pregnancy outcomes: the 2005 WHO global survey on maternal and perinatal health in Latin America. Lancet. 2006; 367:1819-29. | Article | PubMed

3. Hannah ME, Hannah WJ, Hodnett ED, Chalmers B, Kung R, Willan A, Amankwah K, Cheng M, Helewa M, Hewson S, Saigal S, Whyte $H$ and Gafni A. Outcomes at 3 months after planned cesarean vs planned vaginal delivery for breech presentation at term: the international randomized Term Breech Trial. JAMA. 2002; 287:1822-31. | Article | PubMed

4. Press JZ, Klein MC, Kaczorowski J, Liston RM and von Dadelszen P. Does cesarean section reduce postpartum urinary incontinence? A systematic review. Birth. 2007; 34:228-37. | Article | PubMed Abstract | PubMed Full Text

5. Groutz A, Rimon E, Peled S, Gold R, Pauzner D, Lessing JB and Gordon $D$. Cesarean section: does it really prevent the development of postpartum stress urinary incontinence? A prospective study of 363 women one year after their first delivery. Neurourol Urodyn. 2004; 23:26. | Article | PubMed

6. Minkoff H, Powderly KR, Chervenak F and McCullough LB. Ethical dimensions of elective primary cesarean delivery. Obstet Gynecol. 2004; 103:387-92. | Article | PubMed

7. Wu JM, Hundley AF and Visco AG. Elective primary cesarean delivery: attitudes of urogynecology and maternal-fetal medicine specialists. Obstet Gynecol. 2005; 105:301-6. | Article | PubMed

8. Koroukian SM. Relative risk of postpartum complications in the Ohio Medicaid population: vaginal versus cesarean delivery. Med Care Res Rev. 2004; 61:203-24. | Article | PubMed

9. Setse R, Grogan R, Pham L, Cooper LA, Strobino D, Powe NR and Nicholson W. Longitudinal study of depressive symptoms and healthrelated quality of life during pregnancy and after delivery: the Health Status in Pregnancy (HIP) study. Matern Child Health J. 2009; 13:577-87. | Article | PubMed

10. Torkan B, Parsay S, Lamieian M, Kazemnhezhad A and Montazen A. Comparative analysis of life quality in mothers after cesarean section and normal vaginal delivery. Iranian Journal of Nursing and Midwifery Research. 2007; 12.

11. Fabris K L. Persistent post-partum pain after vaginal birth and cesarean section. Periodicum Biologorum. 2011; 133:239-241.

12. Prentice WE. Understanding and managing the healing process through rehabilitation. In: Prentice WE, Voight MI, eds. Techniques in Musculoskeletal Rehabilitation. 2001; 17- 41.

13. Biering K, Nohr EA, Olsen J, Andersen AM, Hjollund NH and Juhl M. Pregnancy-related pelvic pain is more frequent in women with increased body mass index. Acta Obstet Gynecol Scand. 2011; 90:1132-9. | Article | PubMed

14. Almeida EC, Nogueira AA, Candido dos Reis FJ and Rosa e Silva JC. Cesarean section as a cause of chronic pelvic pain. Int I Gynaecol Obstet. 2002; 79:101-4. | Article | PubMed

15. Barber MD, Chen Z, Lukacz E, Markland A, Wai C, Brubaker L, Nygaard I, Weidner A, Janz NK and Spino C. Further validation of the short form versions of the Pelvic Floor Distress Inventory (PFDI) and Pelvic Floor Impact Questionnaire (PFIQ). Neurourol Urodyn. 2011; 30:541-6. | Article | PubMed Abstract | PubMed Full Text 
Walton et al. Physical Therapy and Rehabilitation 2015,

16. Udombhornprabha A, Boonhong J and Tejapongvorachai T. Reliability and validity of the medical outcomes study, a 36-item short-form health survey, (mos sf-36) after one-year hospital discharge of hip fracture patient in a public hospital. International Journal of Collaborative Research on Internal Medicine \& Public Health. 2012; 4.

17. U.S. Population Norms. 2013. I Pdf

18. BMI Classification. The World Health Organization. 2014. I Website

19. Vasanth Andrews, Shelmeridine, Susan, Sultan, Abdul H, Thakar and Ranee. Anal and urinary incontinence $\mathbf{4}$ years after a vaginal delivery. Int Urogynecol Journal. 2012; 10.

20. Torkan B, Parsay S, Lamieian M, Kazemnhezhad A, and Montazen A. Comparative analysis of life quality in mothers after cesarean section and normal vaginal delivery. Iranian Journal of Nursing and Midwifery Research. 2007; 12.

21. Handa VL, Barber MD, Young SB, Aronson MP, Morse A and Cundiff GW. Paper versus web-based administration of the Pelvic Floor Distress Inventory $\mathbf{2 0}$ and Pelvic Floor Impact Questionnaire 7. Int Urogynecol J Pelvic Floor Dysfunct. 2008; 19:1331-5. | Article I PubMed Abstract | PubMed Full Text

22. Movahedi M, Saidi M, Akbari M and Ghasemi M. Effects of Type of Delivery on Development of Stress Urinary Incontinence in Primiparous Mothers. (English). Journal Of Isfahan Medical School. 2013; 31:218-223.

23. Gyhagen M, Bullarbo M, Nielsen TF and Milsom I. The prevalence of urinary incontinence $\mathbf{2 0}$ years after childbirth: a national cohort study in singleton primiparae after vaginal or caesarean delivery. BJOG. 2013; 120:144-51. | Article | PubMed

24. Rortveit G, Daltveit AK, Hannestad YS and Hunskaar S. Urinary incontinence after vaginal delivery or cesarean section. $N$ Engl J Med. 2003; 348:900-7 | Article | PubMed

25. Hansen A, Jensen DV, Wormslev M, Minck H, Johansen S, Larsen EC, Wilken-Jensen C, Davidsen M and Hansen TM. Symptom-giving pelvic girdle relaxation in pregnancy. II: Symptoms and clinical signs. Acta Obstet Gynecol Scand. 1999; 78:111-5. I Article I PubMed

26. Leroy Lda S and Lopes $\mathrm{MH}$. Urinary incontinence in the puerperium and its impact on the health-related quality of life. Rev Lat Am Enfermagem. 2012; 20:346-53. | Article | PubMed

27. Balci E, Gurlevik O, Gun I and Gunay O. The effects of stress urinary incontinence on the quality of life of Turkish women in the reproductive age group. Turkish Journal Of Medical Sciences. 2012; 42:845-851.

28. Lamina $S$ and Agbanusi E. Effect of aerobic exercise training on maternal weight gain in pregnancy: a meta-analysis of randomized controlled trials. Ethiop J Health Sci. 2013; 23:59-64. I PubMed Abstract I PubMed Full Text

29. Miquelutti MA, Cecatti JG and Makuch MY. Evaluation of a birth preparation program on lumbopelvic pain, urinary incontinence, anxiety and exercise: a randomized controlled trial. BMC Pregnancy Childbirth. 2013; 13:154. | Article | PubMed Abstract | PubMed Full Text

30. Stafne SN, Salvesen KA, Romundstad PR, Torjusen IH and Morkved S. Does regular exercise including pelvic floor muscle training prevent urinary and anal incontinence during pregnancy? A randomised controlled trial. BJOG. 2012; 119:1270-80. | Article | PubMed

\section{Citation:}

Walton LM, Abreu C, Jeffus E, Trautwein A and Xavier $S$. Pelvic pain, pelvic organ prolapse, urinary and colorectal distress incidence and relationship to quality of life and birth mode. Phys Ther Rehabil. 2015; 2:1. http://dx.doi.org/10.7243/2055-2386-2-1 